Historical Doses To The Public from

Routine and Accidental Releases of

Tritium \# Lawrence Livermore National Laboratory, 1953 \# 2005

S-R. Peterson, W. Raskob

August 28, 2007

International Conference on Tritium Science and Technology Rochester, NY, United States September 17, 2007 through September 21, 2007 
This document was prepared as an account of work sponsored by an agency of the United States Government. Neither the United States Government nor the University of California nor any of their employees, makes any warranty, express or implied, or assumes any legal liability or responsibility for the accuracy, completeness, or usefulness of any information, apparatus, product, or process disclosed, or represents that its use would not infringe privately owned rights. Reference herein to any specific commercial product, process, or service by trade name, trademark, manufacturer, or otherwise, does not necessarily constitute or imply its endorsement, recommendation, or favoring by the United States Government or the University of California. The views and opinions of authors expressed herein do not necessarily state or reflect those of the United States Government or the University of California, and shall not be used for advertising or product endorsement purposes. 


\title{
HISTORICAL DOSES TO THE PUBLIC FROM ROUTINE AND ACCIDENTAL RELEASES OF TRITIUM - LAWRENCE LIVERMORE NATIONAL LABORATORY, 1953 - 2005
}

\author{
S. Ring Peterson ${ }^{1}$ and Wolfgang Raskob ${ }^{2}$ \\ ${ }^{1}$ Lawrence Livermore National Laboratory, P.O. Box 808, Livermore, CA 94551, USA, peterson49@llnl.gov; ${ }^{2}$ Institut für \\ Kern und Energietechnik (IKET), Bau 433, Forschungszentrum Karlsruhe Technik und Umwelt, Postfach 3640, D-76021 \\ Karlsruhe, Germany
}

Throughout fifty-three years of operations, an estimated 29,300 TBq of tritium have been released to the atmosphere at the Livermore site of Lawrence Livermore National Laboratory; about $75 \%$ of this was released accidentally as gaseous tritium in 1965 and 1970. Routine emissions contributed slightly more than 3,700 $\mathrm{TBq}$ gaseous tritium and about 2,800 TBq tritiated water vapor to the total. Mean annual doses (with 95\% confidence intervals) to the most exposed member of the public were calculated for all years using the same model and the same assumptions. Because time-dependent tritium models require detailed meteorological data that were unavailable for the large releases, ingestion/inhalation dose ratios were derived from experience with UFOTRI. Even with assumptions to assure that doses would not be underestimated, all doses from routine and accidental releases were below the level (3.6 $\mathrm{mSv})$ at which adverse health effects have been documented, and most were below the current regulatory limit of $100 \mu \mathrm{Sv}$ per year from releases to the atmosphere.

\section{INTRODUCTION}

This Tritium Dose Reconstruction (TDR) was undertaken to compile a complete history of routine and accidental releases from the Livermore site of Lawrence Livermore National Laboratory (LLNL) and to calculate tritium doses to the maximally exposed member of the public. For routine releases, annual doses from inhalation and ingestion were calculated using the same model and assumptions for the years 1953 - 2005; for accidental releases, predicted inhalation and ingestion doses accounted for the complex dynamics of tritium movement through the environment following the release. Annual doses prior to 1973 had not been calculated, and doses after 1973 had been calculated with different models and assumptions. If doses had been calculated for accidental releases, they were calculated for inhalation only, with the exception of the 1970 release ${ }^{1 \text { and } 2}$ of gaseous tritium $\left(\mathrm{HT}^{\mathrm{a}}\right)$.

\footnotetext{
${ }^{\mathrm{a}}$ In this paper, gaseous tritium in any form (e.g., $\mathrm{T}_{2}, \mathrm{HT}, \mathrm{DT}$ ) will be referred to as HT. Similarly, HTO will be used for all forms of tritiated water (vapor).
}

\section{METHODS}

The model, DCART, ${ }^{3}$ was developed for the TDR and uses site-specific data when possible. DCART calculates dose to adult, child, and infant and accounts for conversion of HT to tritiated water (HTO) in the environment and the contribution of organically bound tritium (OBT) to ingestion dose. DCART is an equilibrium dose model that runs in an Excel $^{4}$ spreadsheet. Using the risk assessment software, Crystal Ball, ${ }^{5}$ all input parameters are distributed and mean dose and $2.5 \%$ and $97.5 \%$ confidence limits are predicted. To model dose after an accidental release of tritium, a complex dynamic model is needed that accounts for dispersion of the plume, deposition of HT or HTO to soil, and (re)emission of HTO from the soil and its dispersion. Hourly meteorological data are needed for several days after the release. The model must account for rates of uptake of HTO by plants that vary with wind speed and stability class, because ingestion dose can be significant after an accidental release, particularly of HT. Hourly meteorological data for the accidental releases with the greatest potential dose impact were unavailable, so direct use of a time-dependent tritium model had to be ruled out. However, using experience gained from UFOTRI $^{6}$ and 7 , and exploiting the equivalency that can exist between the dose integral over infinite time from an acute release and dose at equilibrium, ${ }^{8}$ ingestion/inhalation ratios, with appropriate uncertainty, were used to determine ingestion doses from inhalation doses calculated using DCART. Doses calculated from these ratios were reduced by assuming that only those plants that could have been growing at the times of the releases were contaminated.

An extensive search of records and files was carried out to collect all available information about tritium release rates from the various facilities and other pertinent data, such as stack parameters. ${ }^{9}$ Excellent documentation of releases, both routine and accidental, was found dating to mid-1956; releases were measured as HT and HTO after 1973. One memo was found from 1954 documenting an accidental release of HTO. ${ }^{10}$ In preparing the input for DCART, many assumptions had to be made, about the release rates before 1956, the fraction 
of total releases that were HT or HTO, and the presence, location, and magnitude of releases from diffuse area sources. The relatively large potential dose impact of small releases from area sources was known from modeling and model testing. ${ }^{11}$

The dispersion model used to calculate the dilution factor $\left(\chi / \mathrm{Q}, \mathrm{s} \mathrm{m}^{-3}\right)$ needed as input for DCART for the routine releases was CAP88-PC; ${ }^{12}$ the wind file for the dispersion modeling was compiled from four years of $15-$ minute wind speeds and directions collected at the LLNL meteorological tower. The uncertainty on the dilution factor, which varied between \pm 25 and $40 \%$, depended on the confidence that could be placed in stack parameters and other variables. HOTSPOT ${ }^{13}$ was the dispersion model used to calculate the dilution factors for the accidental releases. The uncertainty on the dilution factors was $\pm 80 \%$ when meteorological conditions were known and up to $\pm 230 \%$ when generic wind speed and stability class data were compiled from several years of 15-minute data for the month of the release (these variables are seasonal). Dilution factors were calculated for each source and each receptor (Fig. 1).

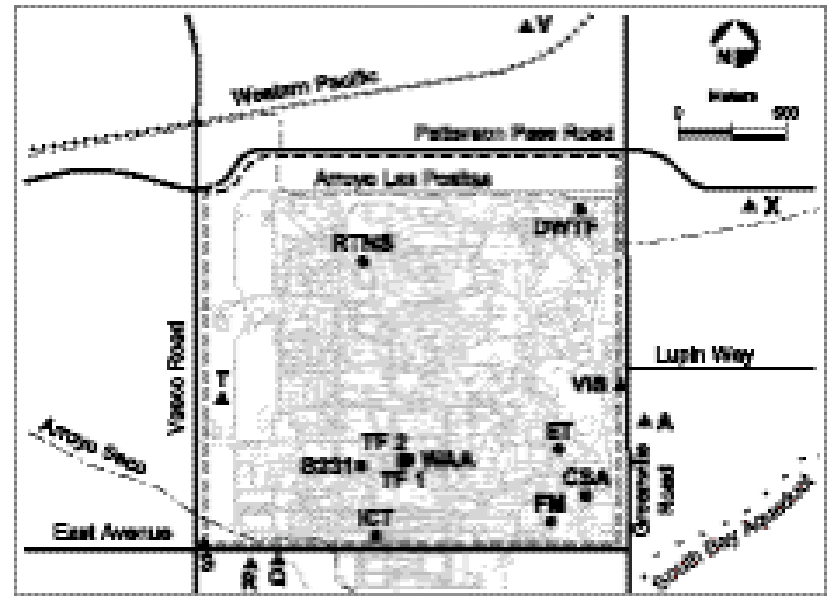

Figure 1. Sources of tritium $(\bullet)$ released from LLNL relative to the locations ( $\boldsymbol{\Delta})$ of the MEI. Tritium was released routinely and accidentally from B231, TF1, and TF2. Routine releases were modeled from area sources (WAA, CSA, ET, FM, and B231) and stacks (ICT, RTNS, and DWTF). The MEI for routine releases was at Locations T (1953 - 1958, Q (1961 and 1974 - 1978), and VIS (all other years). For accidental releases the MEI was at Locations R (1954), Q (1964, 1966), X (1965), V (1970), A (1984), and S (1985).

Because HTO concentrations in air had been measured biweekly starting in 1973 at location VIS (Fig. 1), and because VIS was the location of the maximally exposed individual (MEI) for the majority of years of the TDR, predicted concentrations of HTO in air moisture were compared with the mean annual observations from 1973 through $2005 .^{14}$ The confidence intervals on predictions and observations overlapped for all except the six years when predictions were greater than observations. These results demonstrated that doses would not be underestimated and that reasonable confidence could be placed in the assumptions and modeling approach.

\section{RESULTS AND DISCUSSION}

\section{III.A. Annual Doses ${ }^{14}$ and 15 from Routine Releases, $1953-2005$}

Predicted doses with 95\% confidence intervals to an adult (Fig. 2) show high uncertainty in the first few years of LLNL operations because of assumptions that were made about release rates and speciation of releases into HT and HTO. These confidence intervals are undoubtedly too large, but uncertainty was assessed to assure that doses would not be underestimated. For 1953 through 1972, when releases were reported as either "gas" or "tritium", the assumption that determined the upper confidence limits on doses was that $54 \%$ of the tritium released was HTO. This percentage is the mean observed when more than $22 \mathrm{TBq}$ of tritium (HT + HTO) were released in a year from one stack and operations did not involve HTO; to apply it when true speciation was unknown is conservative (i.e., health protective). After 1973, uncertainty on speciation is minimal, because releases were measured as HT and HTO. Knowing the speciation of releases is important to the confidence that can be placed in dose predictions because, in DCART, a unit release of HT has only about $5 \%$ the dose effect of a unit release of HTO; actual dose impact from HT, of course, varies annually with the fraction of total tritium released that is HT.

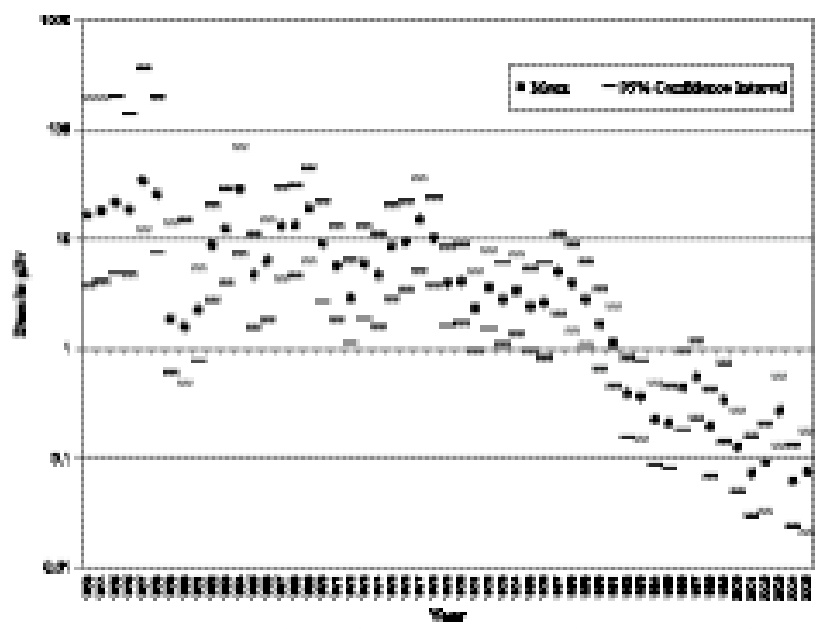

Fig. 2. Mean annual predicted doses and 95\% confidence intervals to the MEI from routine tritium releases from the Livermore site of LLNL. 
The location at which the MEI might have lived (Fig 1) varied depending upon the locations of the sources and the relative magnitudes of the release rates. The MEI was assumed to live at Location $\mathrm{T}$ from 1953 through 1958, at Location Q in 1961 and from 1974 through 1978, and at Location VIS for all other years. Doses were calculated for all years using dispersion modeling, but, because properly measured concentrations of HTO in air can be used to predict a more accurate dose, for those years with observed air concentrations when the MEI was at VIS, doses (Fig. 2) were calculated based on observations.

The highest mean dose to an adult from routine releases for all years was in $1957(34 \mu \mathrm{Sv})$, and the next highest was in $1964(29 \mu \mathrm{Sv})$. The highest mean doses were to an infant, e.g., $42 \mu \mathrm{Sv}$ in 1957 and $35 \mu \mathrm{Sv}$ in 1964. Because of the conservative assumption in DCART that all food in a complete diet is contaminated to the extent possible from predicted or measured concentrations of HTO in air at one specific cubic meter, and because the MEI was assumed to live at the closest structure to the Laboratory, even when that structure was known not to have been a residence, the upper confidence limit on the dose is assumed to have been a dose that could not have been exceeded. The highest dose that could not have been exceeded for the years of LLNL operations was $370 \mu \mathrm{Sv}$ to an adult and $590 \mu \mathrm{Sv}$ to an infant in 1957 due to the high uncertainty. Likely doses would have been much less. No dose (except $120 \mu \mathrm{Sv}$ to an infant in 1964) exceeded $100 \mu \mathrm{Sv}$ from 1959 on.

\section{III.B. Doses from Accidental Releases ${ }^{16}$}

Seven accidental releases were modeled using the ingestion/inhalation ratios derived from UFOTRI. In 1954, about 54 TBq HTO were released from B231 (Fig. 1); all other releases were HT from TF1 or TF2. When meteorological conditions were unknown (in 1954, 1964, and 1966), the conservative assumption was made that the MEI lived at the closest structure that a member of the public could have access to, whether or not this structure was a residence. When meteorological conditions were known, the first structure downwind of the plume was assumed to have been a residence.

Because conservative assumptions were made about the foods that could have been contaminated, the locations of the MEI, and meteorological conditions, the upper confidence limit on the predictions (Fig. 3) is viewed as a dose that could not have been exceeded. The highest predicted dose that could not have been exceeded was $2 \mathrm{mSv}$ to an adult and $3 \mathrm{mSv}$ to a child or infant in 1954. These doses are probably much higher than any received by actual individuals because wind speeds and stability classes were selected so that the distribution of the dilution factor would include maximum probable values, because all food, except grain, was assumed contaminated, and because there was only a $10 \%$ probability that the tritium plume was carried over the nearest structure (Location R).

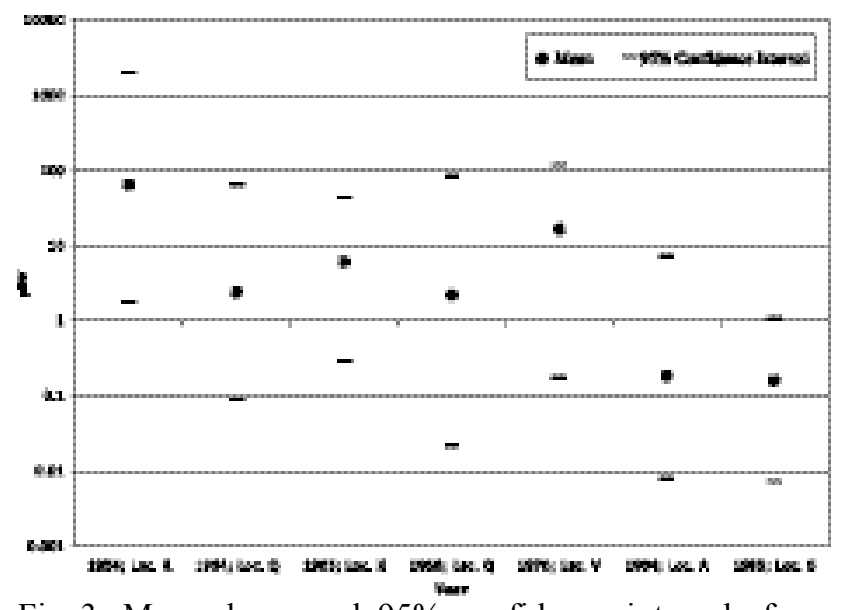

Fig 3. Mean doses and 95\% confidence intervals from accidental releases from the Livermore site of LLNL predicted at locations of the MEI.

The second highest dose that could not have been exceeded $(120 \mu \mathrm{Sv}$ to an adult, $170 \mu \mathrm{Sv}$ to child or infant at Location V) was from the $10,700 \mathrm{TBq}$ release of HT that occurred in 1970. This dose is much lower than either of the other two dose estimates made for this release. One set of doses $^{1}$ was calculated using very conservative assumptions; in the other set of results, ${ }^{2}$ inhalation accounted for $99 \%$ of the dose due to the way emission from the soil was modeled. For the TDR, inhalation dose contributed about $6 \%$ to the total predicted.

The largest release in LLNL history was about 13,000 TBq HT in 1965. The dose that could not have been exceeded (Location X) was only $43 \mu \mathrm{Sv}$ to an adult because of the meteorological conditions during the release and the distance of the MEI from the source. The releases of 1964 and 1966 (both of which were about 450 TBq HT) had higher doses that could not have been exceeded than the 1965 release, but the uncertainty on the predictions raised the upper confidence limits; the mean doses were about one-third the mean dose of 1965 because of assumed meteorology and the assumed location of the MEI (Location Q), close to the source.

\section{CONCLUSIONS}

Even the annual doses that could not have been exceeded have always been well below the regulatory limits of dose to the public. The dose to an infant that was the largest fraction of regulatory dose was $11.8 \%$ in 1957 for a dose of $590 \mu \mathrm{Sv}$ compared with a regulatory limit of $5 \mathrm{mSv}{ }^{17}$ After 1958, all doses to an adult were below the current limit for compliance with 40 Code of 
Federal Regulations Part 61 Subpart H. All doses from accidental releases were well below regulatory limits for annual doses at the times of the releases.

In a Public Health Assessment of the Livermore site ${ }^{18}$, it was concluded that "Acute exposures to [plutonium] and tritium via the inhalation, ingestion, and dermal pathways described in this health assessment resulted in cumulative doses of less than $4 \mathrm{mSv}$ or in chronic exposures less than $1 \mathrm{mSv}$ per year (above background and averaged over five years). These doses are unlikely to produce any adverse health effects and therefore are below levels of public health hazard." The conclusion from the TDR, therefore, echoes and reinforces ATSDR's conclusion that, although some public exposure to tritium releases from LLNL operations probably did occur, estimated maximum exposures were below levels of public health concern, and no adverse health effects would be expected.

This work was performed under the auspices of the U.S. Department of Energy by University of California, Lawrence Livermore National Laboratory under Contract W-7405-Eng-48.

\section{REFERENCES}

1. D.S. MYERS, J.F. TINNEY, and P.H. GUDIKSEN. "Health Physics Aspects of a Large Accidental Tritium Release." Proc. Tritium Symposium, Las Vegas, Nevada, August 28 - September 3, 1971, p. 611, Messenger Graphics (1973)

2. ATSDR. Public Health Assessment. "Community Exposures to the 1965 and 1970 Accidental Tritium Releases." Lawrence Livermore National Laboratory Main Site (USDOE) Livermore, Alameda County, California." Agency for Toxic Substances and Disease Registry. Atlanta, Georgia. (2003)

3. S-R. PETERSON. "Historical Doses from Tritiated Water and Tritiated Hydrogen Gas Released to the Atmosphere from Lawrence Livermore National Laboratory. Part 1. Description of Tritium Dose Model (DCART) for Chronic Releases from LLNL". Lawrence Livermore National Laboratory, Livermore, CA. UCRL-TR-205083-Rev-1 (2006)

4. Microsoft Excel.

5. Decisioneering, Inc. 1515 Arapahoe Street, Suite 1311, Denver, CO, 80202 USA.

6. W. RASKOB. "UFOTRI: Program for Assessing the Offsite Consequences from Accidental Tritium Releases." Report KfK-4605, Kernforschungsaentrum Karlsruhe, Germany (1990)

7. W. RASKOB. "Description of the New Version 4.0 of the Tritium Model UFOTRI including User
Guide.” Report KfK-5194, Kernforschungsaentrum Karlsruhe, Germany (1990)

8. P.J. BARRY. "An Introduction to the Exposure Commitment Concept with Reference to Environmental Mercury." The Monitoring and Assessment Centre, Chelsea College, University of London, MARC Report No. 12 (1979)

9. S-R. PETERSON. "Historical Doses from Tritiated Water and Tritiated Hydrogen Gas Released to the Atmosphere from Lawrence Livermore National Laboratory. Part 2. LLNL Annual Site-Specific Data". Lawrence Livermore National Laboratory, Livermore, CA. UCRL-TR-xxxxxx (2007)

10. C.M. STANHOPE. "Memo to Dusty Meadors. Subject: $\mathrm{T}_{2}$ Accident and Personnel Involved, October 13, 1954." (1954)

11. S-R. PETERSON. "Test of CAP88-PC's Predicted Concentrations of Tritium in Air at Lawrence Livermore National Laboratory." Health Phys 87, 583 (2004)

12. B.S. PARKS. "User's Guide for CAP88-PC, Version 1.0." U.S. Environmental Protection Agency, Office of Radiation Programs, Las Vegas NV; EPA 402-B92-001 (1992)

13. S.G. HOMANN. "HOTSPOT; Health Physics Codes for the PC." Lawrence Livermore National Laboratory, UCRL-MA-106315 (1994)

14. S-R. PETERSON. "Historical Doses from Tritiated Water and Tritiated Hydrogen Gas Released to the Atmosphere from Lawrence Livermore National Laboratory. Part 3. Routine Releases, 1973 - 2005". Lawrence Livermore National Laboratory, Livermore, CA. UCRL-TR-xxxxxx (2007)

15. S-R. PETERSON. "Historical Doses from Tritiated Water and Tritiated Hydrogen Gas Released to the Atmosphere from Lawrence Livermore National Laboratory. Part 4. Routine Releases, 1953 - 1972". Lawrence Livermore National Laboratory, Livermore, CA. UCRL-TR-xxxxxx (2007)

16. S-R. PETERSON. "Historical Doses from Tritiated Water and Tritiated Hydrogen Gas Released to the Atmosphere from Lawrence Livermore National Laboratory. Part 5. Accidental Releases". Lawrence Livermore National Laboratory, Livermore, CA. UCRL-TR-xxxxxx (2007)

17. NCRP. National Committee on Radiation Protection and Measurements. "Maximum Permissible Exposure to Man (April 15, 1958)." U.S. Department of Commerce's Addendum to the U.S. National Bureau of Standards Handbook (1958)

18. ATSDR. Public Health Assessment Lawrence Livermore National Laboratory Main Site (USDOE) Livermore, Alameda County, California." Agency for Toxic Substances and Disease Registry. Atlanta, Georgia. (2004) 